\title{
Extractible Synthesis and Characterization of $\mathrm{Cu}$ (II) Complex with Capric Acid
}

Rehali $\mathrm{H}^{*}$ and Barkat $\mathrm{D}$

Faculty of Science and Engineering Sciences, Department of Industrial Chemistry, University of Biskra, Biskra, BP 145, Algeria

\begin{abstract}
The Copper atom in capric acid copper (II) monomeric complex, having formula of the type $\left[M(H L)_{2} L_{2}\right] \cdot n H_{2} O(M$ : $\mathrm{Cu}(\mathrm{II}) \mathrm{n}=2$ ), ( $\mathrm{HL}$ : capric acid) has been prepared and characterized by physico-chemical studies. The complex has been characterized with the help of elemental analysis, conductance measurements, Electronic spectral (UV-Visible) data suggest that the octahedral environment around the central metal ion. Fourier transform infrared spectrophotometer spectra (IR) confirm the presence of monodentate carboxylate anion $\left.(\Delta v=v a s y C O O-v s y m C O O-)>230 \mathrm{~cm}^{-1}\right)$ in the complex. The thermal behavior of complex was studied by thermogravimetry (DTG), differential thermal analysis (DTA). The final decomposition products namely $\mathrm{Cu}_{2} \mathrm{O}$.
\end{abstract}

Keywords: Capric acid; Metal (II) complexes; IR spectra; UV-VIS spectroscopy; Thermal decomposition

\section{Introduction}

Liquid-liquid extraction is one of the most useful techniques for selective removal and recovery of metal ions from aqueous solutions, applied in purification processes in numerous chemical and metallurgical industries. Carboxylic acids have been studied as extract ants for numerous metals and have been shown to exhibit good extraction and separation efficiency. Decanoic acid, or capric acid, is a saturated fatty acid. Its formula is $\mathrm{CH}_{3}\left(\mathrm{CH}_{2}\right)_{8} \mathrm{COOH}$. Along with capric acid, these total $15 \%$ in goat milk fat Copper, nickel and Cobalt are metals which appear together in real samples, both natural and artificial. However, in excess of these ions in the human body can cause serious harm to health. These metals are significant for environmental surveillance, food control, occupational medicine, toxicology, and hygiene [1]. The carboxyl ate complex of the higher fatty acids with the metal ions have many applications in different industrial spheres such as driers in paints and inks, the components of lubricating greases, stabilizers of plastics, catalysts, the additives at fuel, as well as the corrosion preventive materials, promoters of rubber-steel cord adhesion [2], etc. Therefore metal carboxylate have promising applications depending upon the metal used to make the complex. The synthesis and characterization of complex copper (II)) with capric acid is reported here in.

\section{Experimental}

\section{Reagents}

Capric acid (98\%, Fluka) used as purchased.

Chloroform was pre-equilibrated with aqueous solution which did not contain copper (II).

The ionic strength of the aqueous medium was assumed to be unity $\left(\left[\mathrm{Na}_{2} \mathrm{SO}_{4}\right]=0.33 \mathrm{M}\right)$. The initial concentration of copper is $100 \mathrm{ppm}$.

\section{Materials and measurements}

Conductivity measurements were performed at $25 \pm 0.05^{\circ} \mathrm{C}$ on a conduct meter (DDSJ-308A) with an electrode. The cell constant was determined by use of $\mathrm{KCl}$ standard aqueous solution. The molar conductivity $\left(\Lambda_{\mathrm{M}}\right)$ of the complex was measured using $1.0 \times 10^{-3} \mathrm{~mol} /$ $\mathrm{dm}^{-3}$ solution in dimethyl fumarate (DMF). X-ray diffraction (XRD) was carried out on a Bruker SMART 1000 CCD area diffract meter. An electron microscopy (MEB) coupled energy dispersive spectrometer microanalysis (EDX) is used in chemical composition was also performed. Electronic spectra of complex in chloroform $\left(\mathrm{CHCl}_{3}\right)$ obtained using a spectrophotometer UV-Visible (SHIMADZU UV VIS1240) in the range of 1200-300 nm. Fourier transform infrared spectrophotometer (SHIMADZU FTIR 8400) covering the range $4000-400 \mathrm{~cm}^{-1}$ of the ligands and their metal complex was measured using $\mathrm{KBr}$ discs. Thermogravimetry (TG 70/217) Thristor-Power supplylinse thermal analyzer was used to record simultaneous (DTG and DTA) curves in a static air atmosphere, at a heating rate $10^{\circ} \mathrm{Cmin}^{-1}$ in the temperature range $0-500^{\circ} \mathrm{C}$ using platinum crucible.

\section{Extraction and analytical procedures}

An aqueous copper solution $\left(30 \mathrm{ml}, 1.57 \times 10^{-3} \mathrm{~mol} . \mathrm{L}^{-1}\right)$ was placed in a thermostated vessel at $25 \pm 0,05^{\circ} \mathrm{C}$. To the solution, an equal volume of chloroform solutions containing $1 \times 10^{-3}-4 \times 10^{-2}$ mol. $\mathrm{L}^{-1}$ of capric acid. This time was sufficient since the equilibrium was reached rapidly. After equilibrium, both phases were allowed to stand for more than 20 min for a complete phase separation. The $\mathrm{pH}$ of the solution was adjusted to between 4 and 7, 5 by adding a few drops of $0.1 \mathrm{~mol}$. $\mathrm{L}^{-1} \mathrm{NaOH}$.

The metal ion concentrations were determined in aqueous phase photo metrically at $810 \mathrm{~nm}$ using a Philips ( UV-VIS SP6-36). The metal ion concentrations in the organic phase were calculated from the difference between the metal ion concentrations in the aqueous phase before and after extraction.

*Corresponding author: Rehali $\mathrm{H}$, Faculty of Science and Engineering Sciences, Department of Industrial Chemistry, University of Biskra, Biskra, BP 145, Algeria, Tel: 0335431 60; E-mail: rahal.hanan@yahoo.fr

Received September 21, 2015; Accepted October 13, 2015; Published October 23, 2015

Citation: Rehali H, Barkat D (2015) Extractible Synthesis and Characterization of Cu (II) Complex with Capric Acid. J Nanomed Nanotechnol 6: 331. doi:10.4172/21577439.1000331

Copyright: (C) 2015 Rehali $\mathrm{H}$, et al. This is an open-access article distributed under the terms of the Creative Commons Attribution License, which permits unrestricted use, distribution, and reproduction in any medium, provided the original author and source are credited. 
Citation: Rehali H, Barkat D (2015) Extractible Synthesis and Characterization of Cu (II) Complex with Capric Acid. J Nanomed Nanotechnol 6: 331. doi:10.4172/2157-7439.1000331

\section{Result and Discussion}

\section{General treatment of extraction equilibrium of copper (II) with capric acid}

Capric acid is known to exist as dimer in solvent of low polarity such as chloroform, alkanes (hexane, dichloromethane), toluene, benzene and carbon tetrachloride [3].

The extraction of the metal, by a dimerized capric acid (HL) , in chloroform can be represented by the general equation:

$$
\mathrm{jM}^{2+}+\mathrm{j}(\mathrm{n}+\mathrm{p}) / 2(\mathrm{HL})_{2 \text { org }} \stackrel{\mathrm{K}_{\mathrm{exl}}}{\rightleftharpoons}\left(\mathrm{ML}_{\mathrm{n}} \mathrm{p}(\mathrm{HL})\right)_{\text {jorg }}+\mathrm{jnH}^{+}
$$

Where the subscripts org correspond to organic phases, and $\mathrm{j}$ : degree of polymerization of the complex;

$\mathrm{M}^{2+}$ : Divalent metal

org: Organic phase

aq: Aqueous phase

$(\mathrm{HL})_{2}$ : Capric acid extract ant in dimeric in solvent of low polarity;

$\mathrm{n}$ : Cationic charge;

p: Number of monomeric acid contained in the complex;

$\mathrm{K}_{\text {ex1: }}$ Extraction constant

The extraction constant can be written as the following expression

$$
\mathrm{K}_{\mathrm{exl}}=\frac{\left[\left(\mathrm{ML}_{\mathrm{n}} \mathrm{p}(\mathrm{HL})\right)_{\mathrm{jorg}}\right]\left[\mathrm{H}^{+}\right]^{\mathrm{jn}}}{\left[\mathrm{M}^{+2}\right]^{j}\left[(\mathrm{HL})_{2 \text { org }}\right]^{\mathrm{j}(\mathrm{n}+\mathrm{p}) / 2}}
$$

The distribution coefficient $\mathrm{D}$ of the metal between the organic and aqueous phases may be expressed as follows:

$$
\begin{aligned}
& D=\frac{C_{M, 0 r g}}{C_{M, a q}}=\sum_{j} \sum_{a} j[\mathrm{MLnH} L p] \text { org } /\left[c u^{2+}\right] \cdot \alpha_{M} \\
& =\sum_{j} \sum_{p}\left(j K_{e x}\left[M^{n+}\right] a q^{(j-1)} \alpha_{M}^{-1}\left[(H L)_{2}\right]_{\text {org }}{ }^{n+p} / 2\left[H^{+}\right]^{-n j}\right)
\end{aligned}
$$

Where Morg, Maq are the total concentrations of the metal in the organic and aqueous phases, and the side reaction coefficient allowing for metal complication in the aqueous phase, respectively.

$\alpha_{M}:$ Separation factor metals

If only $(\mathrm{MLn}(\mathrm{HL}) \mathrm{p}) \mathrm{j}$ is responsible for the extraction system, equation (5) is derived from equation (4).

$$
\log D=(j-1) \log \left[M^{n+}\right] a q+\frac{n+p}{2} \log \left[(H l)_{2}\right] \operatorname{org}-n j \log \left[H^{+}\right]-\log \alpha_{M}+\log j+\log \text { Kex }
$$

\section{Extraction of copper (II) with capric acid}

The stoichiometry of the extracted species was determined by analyzing the experimental data. The conventional slope analysis method was used. The experimental results are arranged according to equation (5).

The experimental results are arranged according to equation (5). Figure 1 shows the results Obtained for the extraction of copper (II) or $\mathrm{Cu}$ (II) with solutions of various capric acid concentrations. The degree of extraction of copper (II) increases with increase in $\mathrm{pH}$ and capric acid concentration. In the case of other non-polar solvents such as chloroform, extraction of copper (II) is low. This can be explained by the existence of interactions between molecules that promote capric acid dimer formation in chloroform.

Comparing chloroform to other non-polar solvent, the extraction of copper (II) is significantly improved. This is due to the drive of the water molecules accompany complex extracted into the organic phase is less important in the chloroform. This result is in agreement with previously published work, during the extraction of copper (II) from sulfate medium with capric acid and tri-n-octylphosphine oxide in chloroform [4].

The plots of logarithm the distribution coefficient $\log \mathrm{D}$ versus $\mathrm{pH}$ for various concentration of capric acid[Hl] are straight lines with slope equal to two $(n=2)$, This suggests full neutralization of copper(II) valiancy leading to release of two protons as given by equation (6). The data in Figure 1 also reveal no dependence of copper distribution upon the aqueous copper concentration, there by confirming the monomeric nature of the extracted complex $\left(j=1, \alpha_{\mathrm{Cu}}=1\right)$.

$$
C u^{2+}+\frac{2+p}{2}(H L)_{2 o r g} \Leftrightarrow C u L_{2}(H L)_{p} \text { org }+2 H^{+}
$$

Under the present experimental conditions the concentration of metal in organic phase is negligible compared to the concentration of extractant therefore concentration of dimer was calculated as $\left[(\mathrm{HL})_{2}\right]=[\mathrm{HL}] / 2$ According to equation (4), the number of capric acid molecules involved in the monomeric species can be determined from

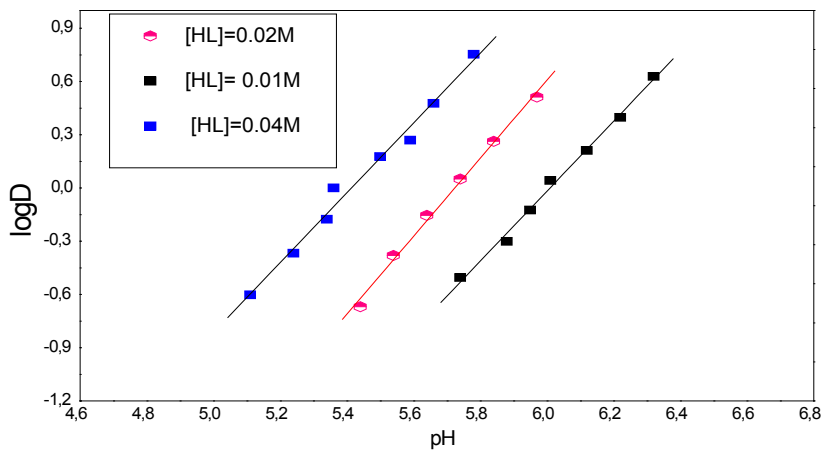

Figure 1: Extraction of copper (II) with capric acid.

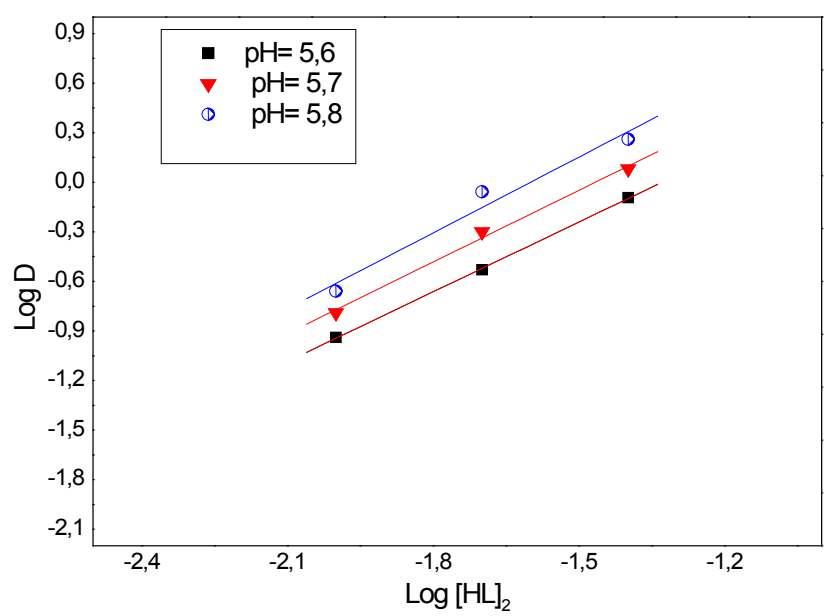

Figure 2: Effect of $\mathrm{pH}$ on the extraction of copper(II) with capric acid in chloroform 
Citation: Rehali H, Barkat D (2015) Extractible Synthesis and Characterization of Cu (II) Complex with Capric Acid. J Nanomed Nanotechnol 6: 331. doi:10.4172/2157-7439.1000331

Page 3 of 5

the slope of the plots of $(\log \mathrm{D})$ against $\log \left[(\mathrm{HL})_{2}\right]$ org at constant $\mathrm{pH}$. The Plots of $\log \mathrm{D}$ versus $\log \left[(\mathrm{HL})_{2}\right]$ org at constant $\mathrm{pH}$ values were also linear with a slope of $(2+p) / 2=2$, i.e., $p=2$, as shown in Figure 2 . This suggest that two molecule of dimeric capric acid take part on the extraction of one ion of copper. This means that only the complex $\mathrm{CuL}_{2}$ $(\mathrm{HL})_{2}$ is extracted into chloroform [4].

The same type of extracted species was reported for the extraction of copper (II) with cyclopentyl acetic acid and $\alpha$-bromostearic acid [5] in benzene. The complex formed has a structure of in which particular places in the coordination sphere of copper ion are occupied in total by four molecules of the extractant. At the same time, two of them, as acid anions, form polarized covalence bonds, and the other two, as non dissociated molecules Coordinate bonds via the carbonyl oxygen atom (Figure 3).

The logarithmic value of Kex of copper (II) can, therefore, be calculated for each experimental point $(\operatorname{logKex}=-7.06)$.

\section{Preparation of the complex}

Organic solution of copper (II) carboxylate was prepared by solvent extraction from an aqueous $\mathrm{CuSO}_{4} 5 \mathrm{H}_{2} \mathrm{O}$ solution. During the extraction operation, the aqueous solution $\mathrm{pH}$ was adjusted at around $\mathrm{pH} 7$ by the addition of dilute $\mathrm{NaOH}$ solution. The initial concentration copper (II) concentration was $0.015 \mathrm{M}$. The initial concentration of free carboxylic acid in the organic phase was $0.1 \mathrm{M}$. The single-metal carboxyl ate solutions were washed with distilled water to remove residual anions and then passed through glass fiber paper and phase separating paper to remove physically entrained water. The precipitates were characterized by X-ray diffraction (XRD) analysis. The chemical composition of the precipitates was determined by energy dispersive $\mathrm{X}$-ray (EDS) spectrometry.

The contents of $\mathrm{C}, \mathrm{O}, \mathrm{Cu}(\mathrm{II})$ were determined by elemental analysis in Table 1 [6].

\section{Molar conductivity measurements}

The very low molar conductance of the complex $\left(\Lambda_{\mathrm{m}}=21.5 \mathrm{~S} . \mathrm{cm}^{2}\right.$. $\mathrm{mol}^{-1}$ ) for the copper (II), complex is measured in temperature $25 \pm 0.05^{\circ} \mathrm{C}$ indicate that this complex nom electrolyte in dimethyl fumarate (DMF) solution [7].

\section{UV- VIS spectra}

The electronic absorption spectra are often very helpful in

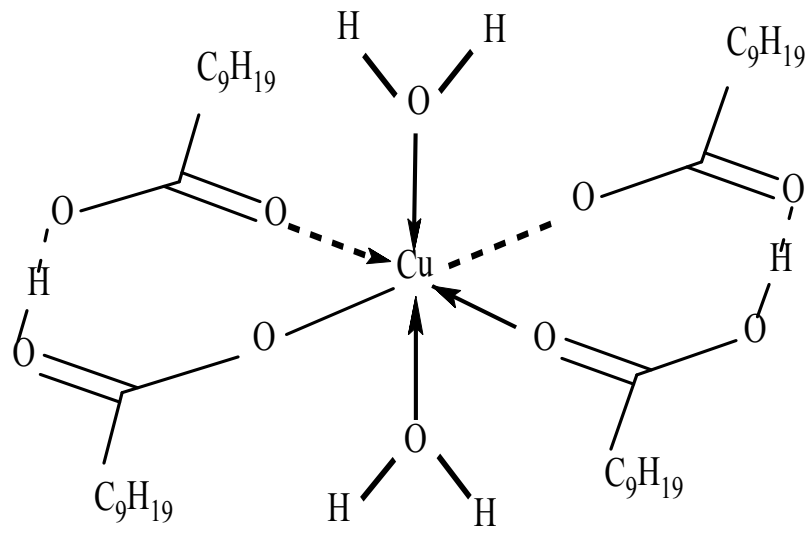

Figure 3: Suggested structures of the complex.

\begin{tabular}{|c|c|c|c|c|}
\hline Complex $\mathrm{L}=\mathrm{C}_{10} \mathrm{H}_{19} \mathrm{O}$ & Color & $\% \mathrm{C}$ & $\% \mathrm{O}$ & $\% \mathrm{Cu}$ \\
\hline$\left[\mathrm{Cu} \mathrm{L} \mathrm{L}_{2}(\mathrm{HL})_{2}\right] \cdot 2 \mathrm{H}_{2} \mathrm{O}$ & blue & 77.55 & 10.5 & 10.34 \\
\hline
\end{tabular}

Table 1: The analytical data of complex at $25^{\circ} \mathrm{C}$

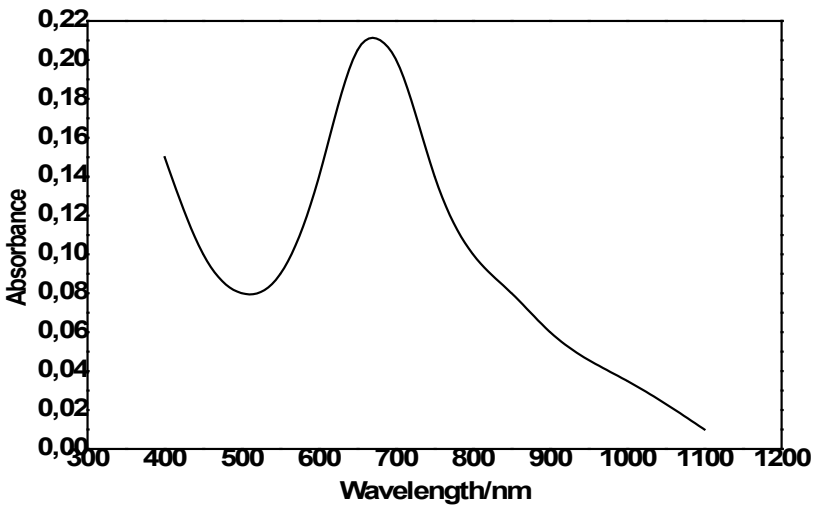

Figure 4: Electronic spectra of $\mathrm{Cu}(\mathrm{II})$ complex.

\begin{tabular}{|c|c|c|c|c|c|}
\hline $\begin{array}{c}\text { Complex } \\
\mathbf{L}=\mathrm{C}_{10} \mathrm{H}_{19} \mathrm{O}\end{array}$ & $\mathbf{V}_{\mathrm{C}=\mathrm{O}} / \mathbf{c m}^{-1}$ & $\mathbf{V a s}_{\text {coo }} / \mathbf{c m}^{-1}$ & $\mathbf{V}_{\text {scoo- }} / \mathbf{c m}^{-1}$ & $\Delta \mathbf{V}_{\text {coo- }} / \mathbf{c m}^{-1}$ & $\mathbf{V}_{\text {M-O }} / \mathbf{c m}^{-1}$ \\
\hline $\boldsymbol{H L}$ & 1711 & - & - & - & - \\
\hline$\left[\mathrm{Cu} \mathrm{L}_{2}(\mathrm{HL})_{2}\right] \cdot 2 \mathrm{H}_{2} \mathrm{O}$ & & 1688 & 1433 & 245 & 478 \\
\hline
\end{tabular}

Table 2: IR data for capric acid and it complex at $25^{\circ} \mathrm{C}$.

\begin{tabular}{|c|c|c|c|c|c|}
\hline Complexes & $\mathrm{T} /{ }^{\circ} \mathrm{C}$ & $\begin{array}{c}\text { Mass } \\
\text { loss } / \%\end{array}$ & DTA $/{ }^{\circ} \mathrm{C}$ & $\begin{array}{c}\text { product } \\
\text { Intermediates }\end{array}$ & color solid \\
\hline \multirow{2}{*}{$\begin{array}{c}{\left[\mathrm{Cu} \mathrm{L}_{2}\right.} \\
\left.(\mathrm{HL})_{2}\right] \cdot 2 \mathrm{H}_{2} \mathrm{O}\end{array}$} & $20-200$ & 3,3 & 100 & $\mathrm{CuL}_{2}(\mathrm{HL})_{2}$ & blue \\
\hline & $200-500$ & 89,9 & $\begin{array}{l}\text { exo/420, } \\
340,300\end{array}$ & $\mathrm{Cu}_{2} \mathrm{O}$ & black \\
\hline
\end{tabular}

Table 3: Thermal decomposition data of Cu (II) complexes with capric acid.

the evaluation of results furnished by other methods of structural investigation. The electronic spectral measurements were used to assign the stereo chemistries of the metal ions in the complexes based on the positions and number of $\mathrm{d}$ - $\mathrm{d}$ transition peaks. The electronic absorption spectra of complexes were recorded in the 1100-400 nm range, at room temperature $[8,9]$.

The copper complex shows a very broad band in the region 660 $650 \mathrm{~nm}$ shown in Figure 4, which is assigned to ${ }^{2} \mathrm{Eg} \rightarrow{ }^{2} \mathrm{~T}_{2 \mathrm{~g}}$ transition, as expected for a six-coordinate $\mathrm{d}^{9}$ species. These Transitions are characteristics of octahedral geometry of the metal atoms $[10,11]$.

\section{IR spectra}

The main bands from the IR spectra of the ligand and its metal complexes are presented in Table 2. The infrared spectrum of the ligand shows a band at $3411 \mathrm{~cm}^{-1}$ which can be attributed to the $\mathrm{OH}$ group. This band is absent in the complex. The strong band of $\mathrm{C}=\mathrm{O}$ at 1711 $\mathrm{cm}^{-1}$, the bands assigned to asymmetric and symmetric vibrations of the $\mathrm{OCH}_{3}$ groups occurring at 2920 and $2849 \mathrm{~cm}^{-1}$ respectively shown in Figure 5. Some of the results of IR spectra analysis are presented in Table 2. In the IR spectra of caprate of copper the band at 1711 $\mathrm{cm}^{-1}$ disappears, which indicates that $\mathrm{C}=\mathrm{O}$ group is not present in the analyzed complex [12]. Strong aliphatic $\mathrm{C}-\mathrm{H}$ stretches are observed at 2930 and $2865 \mathrm{~cm}^{-1}$. These are to be expected due to the long length 


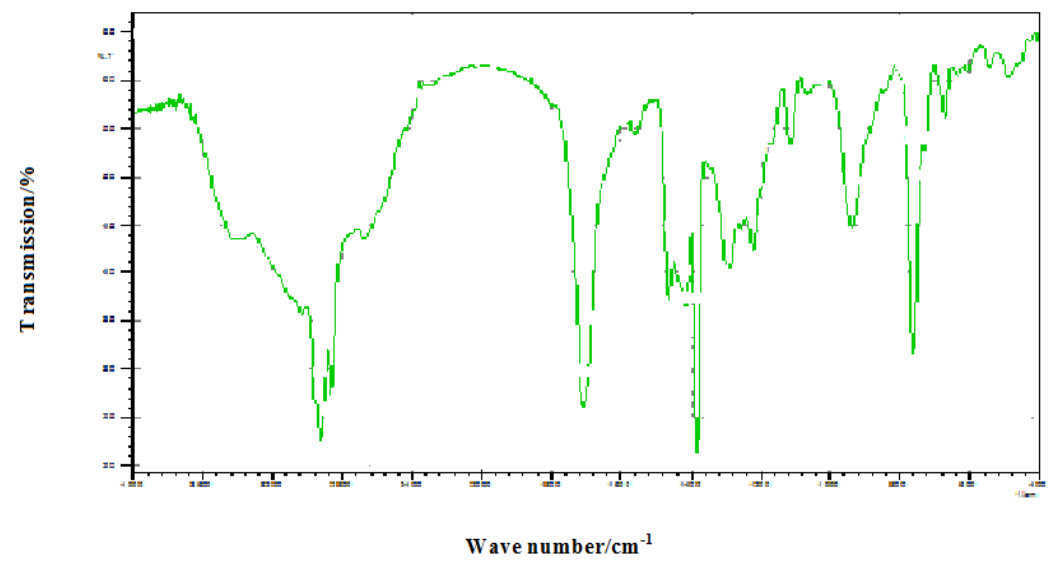

Figure 5: Theinfrared spectrum of capric acid.

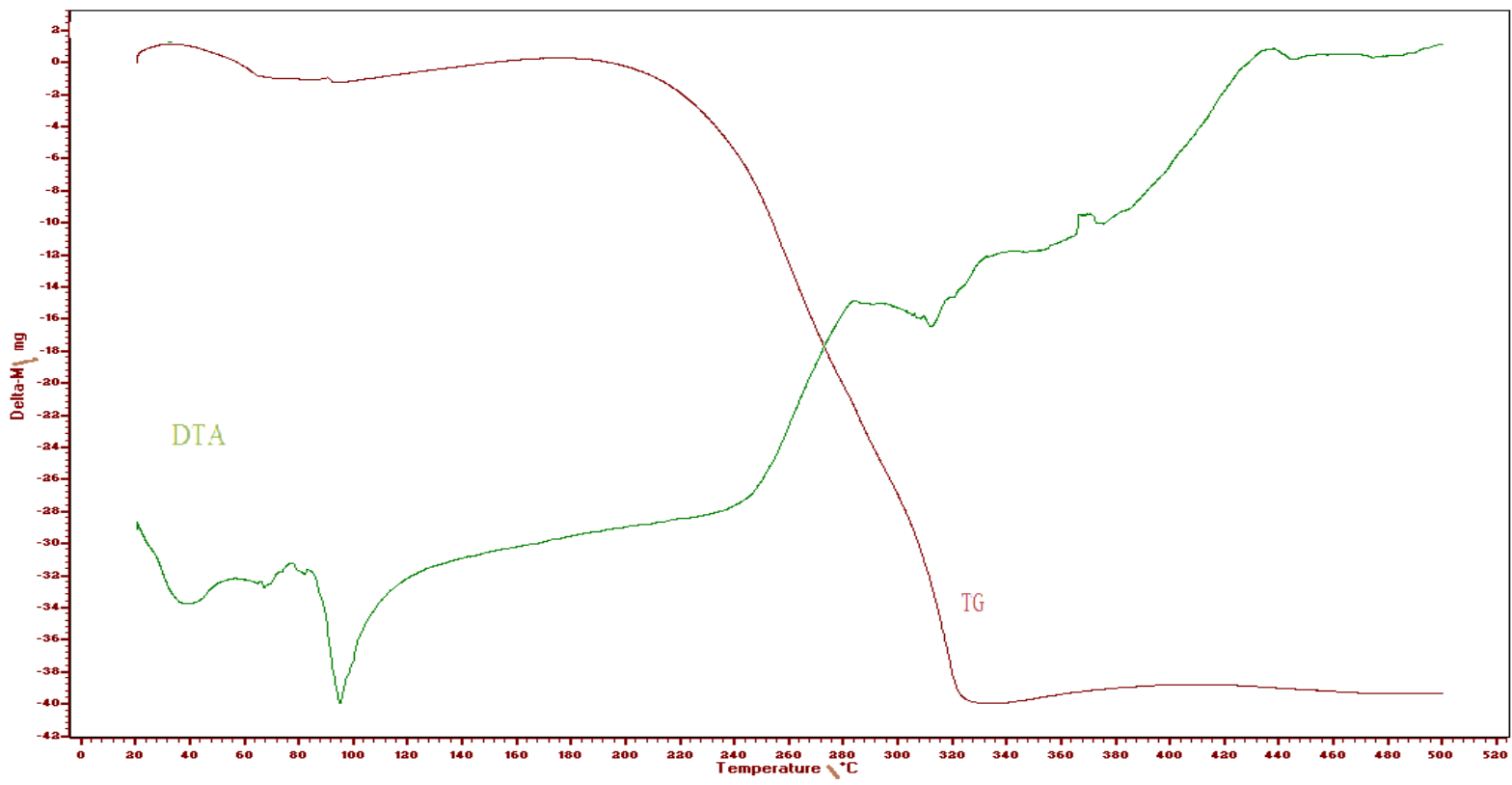

Figure 6: Simultaneous TG- DTA of Cu (II) complex.

of the carbon chain in the carboxylate ligand. When compared to the infrared spectrum for pure capric acid observed in Figure 5.

The absorptions in the range of $1688-1678$ and $1394-1352 \mathrm{~cm}^{-1}$ correspond to the asymmetric and symmetric vCOO- frequencies of the metal bound carboxylates. The large difference in $\Delta \mathrm{vCOO}$ frequencies $\left(\Delta v>230 \mathrm{~cm}^{-1}\right)$ is indicative of monodentate coordination of both the carboxylate groups $[11,12]$. The complex of copper shows strong bands in region 3420 and $3450 \mathrm{~cm}^{-1}$ range assignable toVo-H stretching vibrations of coordinated water molecules [13-15]. The weak band of complex $\mathrm{Cu}$ (II) at $478 \mathrm{~cm}^{-1}$ results from $\mathrm{V}_{\mathrm{M}-\mathrm{O}}$ stretching vibration [16].

\section{Thermal analysis}

The thermal data of the complexes are listed in Table 3. The compositions of the intermediates and the final products are those which best fit with the observed mass losses in the TG studies. Thermo gravimetric results are in good agreement with the corresponding DTA data. The TG/DTA curves of $\left[\mathrm{Cu} \mathrm{L}_{2}(\mathrm{HL})_{2}\right] \cdot 2 \mathrm{H}_{2} \mathrm{O}$ complex show in Figure 6. The mass loss observed between 20 and $200^{\circ} \mathrm{C}$, corresponding to an endothermic peak at $100^{\circ} \mathrm{C}$ is due to dehydration with a loss of two molecule of water (3.33\%). The thermal decomposition occurred in two steps between $200-500^{\circ} \mathrm{C}$ can be observed as three exotherm and two endotherm at $\left(300,340\right.$ and $\left.420^{\circ} \mathrm{C}\right)$ respectively. The final residue, estimated as $\mathrm{Cu}_{2} \mathrm{O}$ had an observed mass of $89.9 \%[12,17]$.

\section{X-Ray Diffraction (XRD)}

The measurement of lattice parameters of the powders was carried out using a Bruker D8 model type diffract meter with copper 
Citation: Rehali H, Barkat D (2015) Extractible Synthesis and Characterization of Cu (II) Complex with Capric Acid. J Nanomed Nanotechnol 6: 331. doi:10.4172/2157-7439.1000331

Page 5 of 5

\begin{tabular}{|c|c|c|}
\hline Complex Cu(II) caprate & \multicolumn{2}{|c|}{$\mathrm{Cu}_{2} \mathrm{O}$} \\
\hline Crystal system & monoclinic & Cubic \\
\hline Space group & $\mathrm{P} 2{ }_{1} / \mathrm{N}$ & $\mathrm{PN} 3 \mathrm{M}$ \\
\hline $\mathrm{a}\left(\mathrm{A}^{\circ}\right)$ & 11,24 & 42,494 \\
\hline $\mathrm{b}\left(\mathrm{A}^{\circ}\right)$ & 4,68 & 42,494 \\
\hline $\mathrm{c}\left(\mathrm{A}^{\circ}\right)$ & 10,24 & 42,494 \\
\hline$\alpha\left({ }^{\circ}\right)$ & 90 & 90 \\
\hline$\beta\left(^{\circ}\right)$ & 92 & 90 \\
\hline $\mathrm{V}\left({ }^{\circ}\right)$ & 90 & 90 \\
\hline $\mathrm{V}\left(\mathrm{A}^{3 \circ}\right)$ & 538 & 76.732 \\
\hline Density $(\mathrm{g} \mathrm{cm}-3)$ & 1.57 & 6.14 \\
\hline$\lambda\left(\mathrm{A}^{\circ}\right)$ & 1.541 & 1.54184 \\
\hline $\mathrm{Z}$ & 2 & 2 \\
\hline$(\mathrm{h}, \mathrm{k}, \mathrm{l})$ & $-2 \leq \mathrm{h} \leq 4,0 \leq \mathrm{K} \leq 2,1 \leq$ & $0 \leq \mathrm{h} \leq 2,0 \leq \mathrm{K} \leq 2,1$ \\
& $\mathrm{~h} \leq 4$ & $\leq \mathrm{h} \leq 3$ \\
\hline
\end{tabular}

Table 4: Data of structure complex Cu (II) Caprate.

anticathode $\lambda$ cuak $=1,54184 \mathrm{~A}^{\circ}$. The recording condition and $0.04^{\circ} \%$ $5 \mathrm{~s}$ to $2 \theta$ taken between $10^{\circ}$ and $90^{\circ}$. The crystallographic data for the complex and oxide of copper are listed in Table 4.

\section{Melting point}

One type of device Melting Point Apparatus Stuart SMP3 Scientific $\left(\operatorname{Tmax}=270^{\circ} \mathrm{C}\right)$ is used. A small amount of product (about $1 \mathrm{mg}$ ) is inserted in a capillary. The capillary then undergoes mentee in temperature of $1^{\circ} \mathrm{C} \cdot \mathrm{min}^{-1}$. The melting temperature is determined by visual observation. Some of these compounds have the feature to go through plastic or gels called phases. Others have temperature melting and very close degradation. These changes make it difficult to visual observation of the melting point of metal carboxylate. The melting point of complex Copper (II) at $178^{\circ} \mathrm{C}$.

\section{Conclusion}

In this research we have used capric acid to extract copper (II) from a sulpahate medium, and we found that this process depends on $\mathrm{pH}$, extractant concentration. Extracted species have an $\left[\mathrm{Cu}(\mathrm{HL})_{2}\right.$ $\left.\mathrm{L}_{2}\right] .2 \mathrm{H}_{2} \mathrm{O}$ stoïchiometry.

One the basis of the results obtained it appears that decanoate of copper (II) were synthesized as hydrated or anhydrous complex. The color of complex Copper (II) is blue. The formula of complex is [Cu $\left.(\mathrm{HL})_{2} \mathrm{~L}_{2}\right] \cdot 2 \mathrm{H}_{2} \mathrm{O}$. Decanoate of analyzed complex is heating in air to $500^{\circ} \mathrm{C}$ they decompose in various ways: $\mathrm{Cu}$ (II) in one step. In the first step the hydrates release the water molecules for complex of copper and form anhydrous complex that the final products of their following oxides: $\mathrm{Cu}_{2} \mathrm{O}$. The complex is found to be non-electrolytic. The results of electronic spectra studies of the complex suggest that the $\mathrm{Cu}$ complex is octahedral geometry, thermal and spectroscopic properties which were determined.

\section{References}

1. Ensafia A, Zarei K, Talanta (2000) 52: 432.

2. Lauo W, Hos Y (1993) J Anal Chem Acta 280: 893

3. Yamada H, Tanaka M (1976) Solvent effects on extraction of copper with capric acid. J Inorg Nucl Chem 38: 1501-1504.

4. Adjal F, Barkat D (2010) synergistic extraction of copper(II) from sulfate medium with capric acid and tri-n-octylphosphine oxide in chloroform. Coord Chem 64: 574-582.

5. Bold L, Bluescu A (1978) Rev Roum Chim 23: 1631.

6. Sova P, Ondrusova D, Jona E, Mojumdar SC , Lalıkova S, et al. (2005) Chimie International Edition 44: 6067.

7. Rigin V (1993) Simultaneous atomic fluorescence spectrometric determination of traces of iron, cobalt and nickel after conversion to their carbonyls and gasphase atomization by microwave-induced plasma. Anal Chim Acta 283: 895901.

8. Geary WJ (1971) The use of conductivity measurements in organic solvents for the characterization of coordination compounds. Coord Chem Rev 7: 81-122.

9. Kumar G, Kumar A, Shishodia N, Garg YP, Yadav BP (2011) Synthesis Spectral Characterization and Antimicrobial Evaluation of Schiff Base $\mathrm{Cu}(\mathrm{II})$ $\mathrm{Ni}(\mathrm{II})$ and $\mathrm{Co}(\mathrm{II})$ Novel Macrocyclic Complexes. Journal of Chemistry 8: 1872 1880.

10. Kurdekar GS, Sathisha MP, Budagumpi S, Kulkarni NV, Revankar VK, et al. (2011) Synthesis, characterization, antibiogram and DNA binding studies of novel $\mathrm{Co}(\mathrm{II}), \mathrm{Ni}(\mathrm{II}), \mathrm{Cu}(\mathrm{II})$, and $\mathrm{Zn}(\mathrm{II})$ complexes of Schiff base ligands with quinoline core. Med Chem Resdoi 20: 421-429.

11. Lever ABP (1984) Inorganic Electronic Spectroscopy. (2ndedn), Elsevier, Amsterdam.

12. Olmez H, Arslan F, Icbudak H (2004) Spectrothermal studies on $\mathrm{Co}(\mathrm{II})$, Ni(II), $\mathrm{Cu}(\mathrm{II})$ and $\mathrm{Zn}(\mathrm{II})$ salicylato (1,10-phenanthroline) complexes. J Therm Anal Calorim 76: 793-800.

13. Sandra SK, Blaga CR, Aleksandra K (2007) Thermal behaviour of Co(II), Ni(II) $\mathrm{Cu}(\mathrm{II}), \mathrm{Zn}(\mathrm{II}), \mathrm{Hg}(\mathrm{II})$ and $\mathrm{Pd}(\mathrm{II})$ complexes with isatin- $\beta$-thiosemicarbazone. Therm Anal Cal 90: 525-531.

14. Premkumar T, Govindarajan S (2006) Divalent transition metal complexes of 3,5-pyrazoledicarboxylate J Therm Anal Cal 84: 395-399.

15. Lever ABP (1968) Inorganic Electronic Spectroscopy, Elsevier, Amsterdam.

16. Nakamoto K (2006) Infrared and Raman Spectra of Inorganic and Coordination Compounds. (3rdedn), Wiley Interscience, New York.

17. Rozyckia C (1981) Chem Anal (Warsaw) 26: 37. 